BMJ Open

Diabetes

Research

\& Care

\section{Impact of HCV infection and ethnicity on incident type 2 diabetes: findings from a large population-based cohort in British Columbia}

To cite: Jeong D, Karim ME, Wong S, et al. Impact of HCV infection and ethnicity on incident type 2 diabetes: findings from a large population-based cohort in British Columbia. BMJ Open Diab Res Care 2021;9:e002145. doi:10.1136/ bmjdrc-2021-002145

- Supplemental material is published online only. To view, please visit the journal online (http://dx.doi.org/10.1136/ bmjdrc-2021-002145).

Received 22 January 2021 Accepted 9 May 2021

Check for updates

(C) Author(s) (or their employer(s)) 2021. Re-use permitted under CC BY-NC. No commercial re-use. See rights and permissions. Published by BMJ.

For numbered affiliations see end of article.

Correspondence to Dr Naveed Zafar Janjua; naveed.janjua@bccdc.ca

\section{ABSTRACT}

Introduction Increasing evidence indicates that chronic hepatitis $\mathrm{C}$ virus (HCV) infection is associated with higher risk of diabetes. Previous studies showed ethnic disparities in the disease burden of diabetes, with increased risk in Asian population. We described the incidence of type 2 diabetes related to HCV infection and assessed the concurrent impact of $\mathrm{HCV}$ infection and ethnicity on the risk of diabetes.

Research design and methods In British Columbia Hepatitis Testers Cohort, individuals were followed from HCV diagnosis to the earliest of (1) incident type 2 diabetes, (2) death or (3) end of the study (December 31, 2015). Study population included 847021 people. Diabetes incidence rates in people with and without HCV were computed. Propensity scores (PS) analysis was used to assess the impact of HCV infection on newly acquired diabetes. PS-matched dataset included 117184 people. We used Fine and Gray multivariable subdistributional hazards models to assess the effect of HCV and ethnicity on diabetes while adjusting for confounders and competing risks. Results Diabetes incidence rates were higher among people with HCV infection than those without. The highest diabetes incidence rate was in South Asians with HCV (14.7/1000 person-years, $95 \% \mathrm{Cl} 12.87$ to 16.78). Compared with Others, South Asians with and without HCV and East Asians with HCV had a greater risk of diabetes. In the multivariable stratified analysis, HCV infection was associated with increased diabetes risk in all subgroups: East Asians, adjusted HR (aHR) 3.07 (95\% $\mathrm{Cl} 2.43$ to 3.88); South Asians, aHR 2.62 (95\% $\mathrm{Cl} 2.10$ to 3.26); and Others, aHR 2.28 (95\% $\mathrm{Cl} 2.15$ to 2.42$)$.

Conclusions In a large population-based linked administrative health data, HCV infection was associated with higher diabetes risk, with a greater relative impact in East Asians. South Asians had the highest risk of diabetes. These findings highlight the need for care and screening for HCV-related chronic diseases such as type 2 diabetes among people affected by HCV.

\section{INTRODUCTION}

Hepatitis $\mathrm{C}$ virus (HCV) infection is the leading cause of liver-related morbidity and mortality, and is also associated with increased risk of non-liver-related morbidities, including renal and cardiovascular diseases,

\section{Significance of this study}

What is already known about this subject?

- Increasing evidence indicates that hepatitis C virus ( $\mathrm{HCV}$ ) infection is associated with higher diabetes risk. Studies show ethnic disparities in diabetes burden, with increased risk in the Asian population. However, evidence on the ethnic disparity in risk of diabetes associated with $\mathrm{HCV}$ infection is scarce.

What are the new findings?

- In this analysis, we described the incidence of diabetes mellitus by HCV infection and assessed the ethnic disparity in the impact of HCV on diabetes risk.

- The findings showed that HCV infection was associated with a greater risk of type 2 diabetes.

- The incidence of diabetes mellitus was greater among individuals with chronic HCV infection compared with those without HCV infection.It was revealed that in this large population-based cohort in British Columbia, Canada, South Asian people with and without HCV infection had the highest risk of diabetes; however, HCV infection had the greatest relative impact on incident diabetes among East Asian people.

How might these results change the focus of research or clinical practice?

- HCV infection could increase the risk of developing diabetes if the infection is not diagnosed and treated timely. In addition, existing disparities in diabetes burden could be further exacerbated by HCV infection.

- Early diagnosis, treatment and elimination of HCV infection may contribute to reducing the overall incidence of type 2 diabetes as well as the ethnic disparity in the overall diabetes burden.

- People with chronic HCV infection may benefit from continuous monitoring and management of metabolic diseases such as diabetes mellitus. 
and metabolic diseases such as type 2 diabetes. ${ }^{1-3}$ There is growing evidence in the literature that people affected by HCV have a greater risk of developing diabetes, ${ }^{4-7}$ despite some conflicting findings in previous population-based studies. ${ }^{8-10}$ Although the pathogenesis of HCV-related diabetes mellitus is less clear, some possible underlying mechanisms include the interaction of HCV core proteins with hepatocytes disrupting the insulin signaling cascade and impairing the pancreatic $\beta$-cell function involved in glucose metabolism. ${ }^{711}$ This leads to increased insulin resistance in individuals with chronic HCV infection. In addition, liver damage and inflammation caused by HCV infection in these individuals could further increase the risk of diabetes. ${ }^{12}$

It has also been suggested that the impact of HCV infection on diabetes mellitus may vary across different ethnic groups, as HCV-related morbidity and mortality differ by ethnicity. ${ }^{13}{ }^{14}$ For instance, in a US study conducted among people with HCV infection, Latin American people had the highest prevalence of pre-diabetes, followed by African-American, and white people $(70 \%$, $50 \%, 12 \%$, respectively) ${ }^{15}$ Studies based in the USA and Europe have shown significant ethnic disparities in the overall distribution of diabetes, with non-white people having a higher prevalence. ${ }^{16-19}$ Asian people had a high prevalence of cardiometabolic diseases such as type 2 diabetes and hypertension compared with other ethnic groups even at lower body mass index (BMI). ${ }^{16}$ The distribution of diabetes according to HCV infection status across different ethnic groups in Canada remains unknown. Major ethnic groups in Canada include people from South and East Asia; according to the 2016 Census, there were more than 6 million people in Canada who reported being of Asian ancestry, with Chinese and Indian being the two most commonly reported ancestries. ${ }^{20}$ In British Columbia (BC), close to $30 \%$ of the population are of Asian origins, most of whom are foreign-born, ${ }^{20}$ from countries that have a high prevalence of $\mathrm{HCV}^{21}$

In BC, there have been more than 70,000 people diagnosed with HCV infection and about 460,000 people diagnosed with diabetes. ${ }^{22-24}$ As people living with HCV infection and diabetes concurrently have greater morbidity and mortality risks, ${ }^{6} 725$ identifying population subgroups with higher comorbidity of HCV infection and diabetes would serve as valuable evidence to inform targeted HCV screening and management strategies to reduce disease burden related to diabetes. This study analysed population-based data from the BC Hepatitis Testers Cohort (BC-HTC) ${ }^{26}$ to assess the impact of $\mathrm{HCV}$ infection on the incidence of type 2 diabetes, and to investigate the differing impact of HCV infection on diabetes risk across ethnic groups in BC.

\section{RESEARCH DESIGN AND METHODS}

\section{Data source, design and study population}

This analysis was performed using data from the BC-HTC, a longitudinal cohort study that includes data on $\sim 1.3$ million people who are tested for $\mathrm{HCV}$ at the $\mathrm{BC}$ Centre for Disease Control (BCCDC) Public Health Laboratory or reported as a case of HCV in BC since 1990. This population-based cohort is integrated through a personal health number with various administrative healthcare datasets such as medical visits, emergency visits, hospital discharge data, drug dispensations, cancer registry as well as vital statistics. The methodology and data linkages of BC-HTC have been described elsewhere. ${ }^{26}$ Data linkages to create the BC-HTC were enabled under the auspices of the BCCDC's public health mandate and were reviewed and approved by the University of British Columbia Behavioural Research Ethics Board (No: H14-01649).

\section{Study sample and variables}

People in the BC-HTC who have ever tested for anti-HCV by December 31, 2014, were included in this analysis. This date was chosen to allow sufficient follow-up time to measure incident cases of diabetes. We excluded individuals who (1) had a death date prior to or on the same day as HCV diagnosis; (2) had a prevalent diagnosis of type 1 or type 2 diabetes at baseline; (3) had no follow-up; (4) had missing information on sex, age at diagnosis or material/social deprivation; or (5) were HCV positive and started HCV treatment but did not meet 12-week eligibility criteria (figure 1). Online supplemental table 1 shows criteria and data sources for the BC-HTC. Diabetes mellitus was defined at the occurrence of the second of two physician visits, within 1 year, or one hospitalization diagnostic code for diabetes mellitus, or the prescription of at least two oral hypoglycemic drugs or insulin within 1 year. This definition is based on a previously validated algorithm to identify diabetes from administrative data, ${ }^{27}$ modified with additional information on medication dispensations and ICD-9/10 supplementary codes. In this analysis, we defined HCV-positive individuals as those who had a positive result for HCV laboratory test (antibody, RNA PCR or genotype) or confirmed as HCV case or determined from HCV treatment dispensation. HCV-negative individuals included those who had a negative test result on their last test. The baseline for HCV-positive individuals was the earliest of the first positive HCV test date or reported as HCV or treatment initiation. For HCV-negative individuals, the baseline was the last date where they had a negative anti-HCV or HCV RNA test. Ethnicity was determined with two validated name recognition programs, Onomap and Nam Pechan, ${ }^{28} 29$ and classified as 'South Asian' (Pakistani, Indian, Bangladeshi, Nepalese, Sri Lankan), 'East Asian' (Chinese, Japanese, Korean) and 'Other' (all other residents of BC including white, Indigenous, black, Latin American, Pacific Islander, Central/West Asian, Filipino and Southeast Asian). Individuals were followed from the baseline to the earliest of (1) incident case of type 2 diabetes, (2) death (competing risk), (3) end of the study (December 31, 2015). As potential confounders, the following covariates were assessed at baseline: sex, age at HCV diagnosis (categorized as $<25,25-34,35-44$, 
Tested for anti-HCV in the BC Hepatitis Testers Cohort by December 31, 2014 $\mathrm{n}=955852$

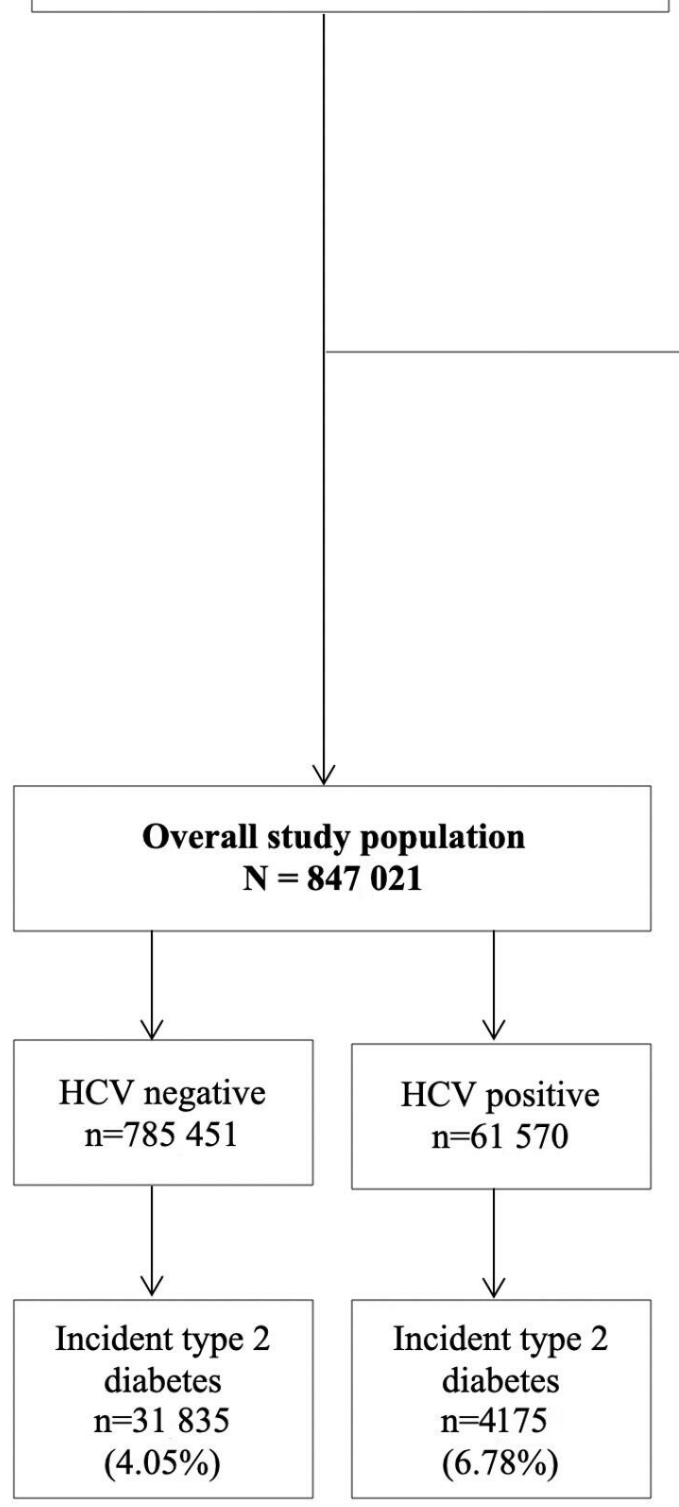

Excluding individuals with:

- Death date prior to or on the date of $\mathrm{HCV}$ diagnosis $(\mathrm{n}=2874)$

- No follow-up time ( $\mathrm{n}=495)$

- Prevalent type 1 diabetes ( $\mathrm{n}=13$ 371)

- Prevalent type 2 diabetes ( $n=86725)$

- Missing information on sex $(n=113)$

- Missing information on age $(n=6)$

- Missing information on material/social deprivation $(\mathrm{n}=4732)$

- HCV positive individuals who started treatment but did not meet 12 weeks eligibility criteria $(\mathrm{n}=515)$

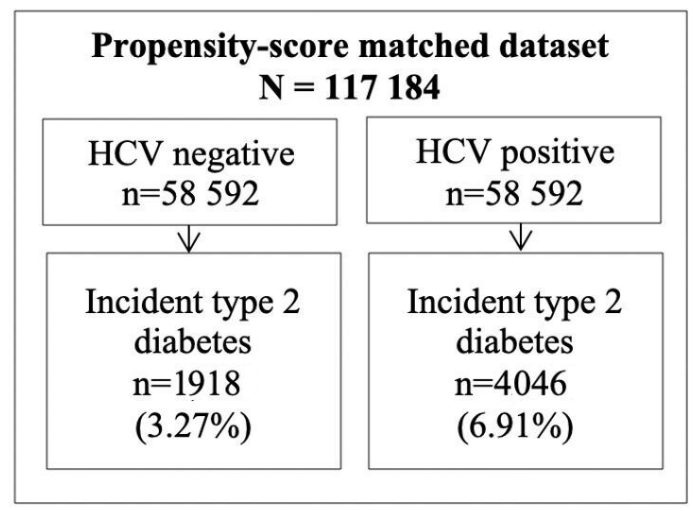

Figure 1 Study inclusion flowchart based on the 1990-2015 British Columbia Hepatitis Testers Cohort. BC, British Columbia; HCV, hepatitis C virus.

$45-55$, and $\geq 55$ ), HBV/HIV infection, cirrhosis, chronic kidney disease, end-stage renal disease, ischemic heart disease, hypertension, statin use, mood and anxiety disorder, obesity, alcohol use disorder, injection drug use, and social and material deprivation quintiles. Material and social deprivation quintiles are based on the Quebec Index of Material and Social Deprivation ${ }^{30}$ which combines six indicators related to health and welfare that represent material or social deprivation based on Canadian census data. These indicators are (1) proportion of persons without high school diploma; (2) ratio of employment to population; (3) average income; (4) proportion of persons separated, divorced, widowed; (5) the proportion of single-parent families; and (6) proportion of people living alone. Online supplemental table 2 includes all variables' definitions.

\section{STATISTICAL ANALYSIS}

Individuals who are living with chronic HCV infection may have different characteristics compared with those without infection. Therefore, we computed standardized mean difference (SMD) ${ }^{31}$ to compare the differences in the baseline characteristics between people with and without HCV. Most covariates had an SMD $>0.2$, indicating an imbalance. ${ }^{32}$ To assess the impact of HCV infection on diabetes risk while adjusting for the differences in baseline characteristics, we estimated propensity scores (PS) 
based on age at HCV diagnosis, duration of follow-up, sex, material/social deprivation quintiles, HBV/HIV infection, mood and anxiety disorders, obesity, alcohol use disorder and injection drug use. The covariate selection for PS model was based on whether the covariates are risk factors of diabetes, or confounders in the relationship between HCV and diabetes, ${ }^{33}$ to create balance on these variables. Individuals with $\mathrm{HCV}$ infection were matched one to one with individuals without infection, without replacement, according to PS. ${ }^{34} \mathrm{~A}$ caliper of 0.1 was selected in matching to minimize differences between matched individuals. ${ }^{35}$ PS matching provided the average treatment effect on the treated (ATT). As a sensitivity analysis, we conducted inverse probability of treatment weighting (IPTW) estimating ATT based on PS. ${ }^{36}$ In addition, as a further sensitivity analysis, we estimated PS in each subgroup separately and matched on PS within each subgroup.

Cumulative diabetes incidence curves and incidence rates per 1000 person-years of follow-up (PYFU) were calculated in the overall study population by HCV infection status, for each ethnic group. The incidence rates were compared with Wald test. We created a composite variable that combines HCV infection and ethnicity to assess and compare the risk of diabetes across the six subgroups (Other/East Asian/South Asian without HCV infection; Other/East Asian/South Asian with HCV infection). Then, a multivariable Fine-Gray proportional hazards model $^{37}$ was used to compute adjusted subdistributional hazard ratios (aHR) for diabetes risk in each subgroup. Finally, we conducted a stratified analysis to compute aHR for the effect of HCV infection on diabetes by ethnicity. To adjust for residual confounding, we employed a double-robust approach by adjusting for covariates again in the Fine-Gray models after PS matching. ${ }^{38}$ To assess the effect modification of HCV infection by ethnicity, we included an interaction term in the multivariable model and performed a likelihood ratio test based on the analysis of deviance. In the sensitivity analysis using the IPTW method, the Fine-Gray models were fit in the overall dataset with the IPW for ATT. The multivariable Fine-Gray model with IPTW also assessed the interaction term. The analytic dataset was created using SAS/STAT software V.9.4 ${ }^{39}$ and statistical analyses were performed using R, V.3.6.1. ${ }^{40}$

\section{RESULTS}

\section{Study population characteristics}

Between January 1, 1990, and December 31, 2014, 955852 people had received at least one anti HCV test in BC. After applying exclusion criteria, the overall study population included 847021 people (figure 1). Among these, 61570 individuals had a positive HCV diagnosis, and 785451 individuals had a negative HCV diagnosis. People with HCV infection had longer follow-up, were more often materially and socially deprived, and more often had alcohol use disorder and injection drug use compared with those without HCV infection (table 1). After PS matching, the matched dataset included 58592 individuals with HCV infection and 58592 individuals without infection. The SMDs were $<0.2$ for all covariates except for ethnicity in the matched dataset. Table 1 compares the baseline characteristics in the overall study population and matched dataset and presents their respective SMDs.

\section{Incident diabetes by HCV infection status and ethnicity}

Overall, there were 36010 incident cases of diabetes. The incidence rates of diabetes were higher in people with HCV infection compared with those without HCV infection, in the overall study population and all ethnicities $(\mathrm{p}<0.001)$ (online supplemental table 3$)$. In the overall study population, among people without HCV infection, there were 5.4 cases of diabetes per 1000 PYFU (95\% confidence interval (CI) 5.34 to 5.46) and among people with HCV infection, 5.85 cases per 1000 PYFU (95\% CI 5.68 to 6.03$)$. In East Asian people, among those without infection, the incidence of diabetes was 6.46/1000 PYFU (95\% CI 6.25 to 6.67 ) and among people with infection, 9.48/1000 PYFU (95\% CI 8.15 to 11.02). In South Asian people, diabetes incidence was 9.5/1000 PYFU (95\% CI 9.17 to 9.84 ) among people without infection and 14.7/1000 PYFU (95\% CI 12.87 to 16.78 ) among people with infection. In all other $\mathrm{BC}$ residents, the incidence of diabetes was 5.02/1000 PYFU (95\% CI 4.96 to 5.08) in people without infection and 5.56/1000 PYFU (95\% CI 5.39 to 5.74$)$ in those with infection. The 15 -year cumulative incidences of diabetes were greater in East Asian and South Asian people compared with Others (figure 2).

\section{PS analysis of the relationship between HCV infection and diabetes}

In the Fine-Gray model fit in the PS-matched dataset, after adjusting for the competing risk of mortality and potential confounders, the adjusted subdistributional HR (aHR) for the association of HCV infection with incident diabetes was 2.32 (95\% CI 2.20 to 2.45$)$, suggesting that more than twice as many individuals with HCV infection are experiencing newly diagnosed type 2 diabetes compared with individuals without HCV infection (table 2). In the dataset weighted with IPW ATT, the aHR associated with incident type 2 diabetes was 2.29 (95\% CI 2.17 to 2.42), consistent with the results from the PS-matched dataset. Other factors associated with increased incidence of diabetes included older age at HCV diagnosis, history of obesity, HIV infection, mood and anxiety disorder, alcohol use disorder and injection drug use.

\section{The effect of ethnicity in the HCV-related diabetes}

Table 3 presents the aHR for each subgroup of the composite variable combining $\mathrm{HCV}$ infection and ethnicity. With 'Other without HCV infection' as the reference, East Asians without HCV infection had a slightly higher hazard (aHR 1.10 (95\% CI 0.93 to 
Table 1 Baseline characteristics of HCV negative and positive individuals in the overall study population and the propensity score (PS)-matched dataset, from the British Columbia Hepatitis Testers Cohort 1990-2015

\begin{tabular}{|c|c|c|c|c|c|c|}
\hline \multirow[b]{2}{*}{ Covariate } & \multicolumn{3}{|c|}{ Overall study population } & \multicolumn{3}{|c|}{ PS-matched dataset* ${ }^{*}$} \\
\hline & $\begin{array}{l}\text { HCV negative } \\
(\mathrm{n}=785451)\end{array}$ & $\begin{array}{l}\text { HCV positive } \\
(n=61570)\end{array}$ & SMD & $\begin{array}{l}\text { HCV negative } \\
(n=58592)\end{array}$ & $\begin{array}{l}\text { HCV positive } \\
(n=58592)\end{array}$ & SMD \\
\hline $\operatorname{Sex}(\%)$ & & & 0.413 & & & 0.014 \\
\hline Female & $434731(55.3)$ & $21694(35.2)$ & & 21054 (35.9) & $20665(35.3)$ & \\
\hline Male & $350720(44.7)$ & $39876(64.8)$ & & 37927 (64.7) & $37538(64.1)$ & \\
\hline Age at HCV diagnosis (\%) & & & 0.439 & & & 0.037 \\
\hline$<25$ & $122524(15.6)$ & $4409(7.2)$ & & $4485(7.7)$ & $4326(7.4)$ & \\
\hline $25-34$ & $196472(25.0)$ & $13485(21.9)$ & & $12109(20.7)$ & $12749(21.8)$ & \\
\hline $35-44$ & $172656(22.0)$ & $20088(32.6)$ & & $18302(31.2)$ & $18674(31.9)$ & \\
\hline $45-54$ & $125087(15.9)$ & $15300(24.8)$ & & $15032(25.7)$ & $14604(24.9)$ & \\
\hline$\geq 55$ & $168712(21.5)$ & $8288(13.5)$ & & $8664(14.8)$ & $8239(14.1)$ & \\
\hline Follow-up duration, mean years (SD) & $7.50(5.4)$ & $11.59(6.4)$ & 0.687 & $11.24(5.97)$ & $11.42(6.42)$ & 0.029 \\
\hline Ethnicity (\%) & & & 0.360 & & & 0.241 \\
\hline Other† & $656110(83.5)$ & $58137(94.4)$ & & $51401(87.7)$ & 55197 (94.2) & \\
\hline East Asian & 78135 (9.9) & $1618(2.6)$ & & $4465(7.6)$ & $1602(2.7)$ & \\
\hline South Asian & $51206(6.5)$ & $1815(2.9)$ & & $2726(4.7)$ & $1793(3.1)$ & \\
\hline Material DQ (\%) & & & 0.353 & & & 0.009 \\
\hline Q1 (most privileged) & $175410(22.3)$ & $8242(13.4)$ & & $8004(13.7)$ & $8052(13.7)$ & \\
\hline Q2 & $154413(19.7)$ & 9764 (15.9) & & $9357(16.0)$ & $9445(16.1)$ & \\
\hline Q3 & $157151(20.0)$ & $10946(17.8)$ & & $10443(17.8)$ & $10567(18.0)$ & \\
\hline Q4 & $157680(20.1)$ & 14117 (22.9) & & $13491(23.0)$ & 13432 (22.9) & \\
\hline Q5 (most deprived) & 140797 (17.9) & $18501(30.0)$ & & $17297(29.5)$ & $17096(29.2)$ & \\
\hline Social DQ (\%) & & & 0.362 & & & 0.009 \\
\hline Q1 (most privileged) & $141254(18.0)$ & $6321(10.3)$ & & $6303(10.8)$ & $6236(10.6)$ & \\
\hline Q2 & $139115(17.7)$ & $7726(12.5)$ & & 7538 (12.9) & 7560 (12.9) & \\
\hline Q3 & $143967(18.3)$ & $10167(16.5)$ & & $9720(16.6)$ & $9826(16.8)$ & \\
\hline Q4 & $164587(21.0)$ & $13022(21.1)$ & & $12387(21.1)$ & 12503 (21.3) & \\
\hline Q5 (most deprived) & $196528(25.0)$ & 24334 (39.5) & & 22644 (38.6) & 22467 (38.3) & \\
\hline HBV infection (\%) & $10781(1.4)$ & $947(1.5)$ & 0.014 & 744 (1.3) & $821(1.4)$ & 0.011 \\
\hline HIV infection (\%) & $1596(0.2)$ & $1676(2.7)$ & 0.211 & $917(1.6)$ & $939(1.6)$ & 0.003 \\
\hline Cirrhosis (\%) & $4919(0.6)$ & $877(1.4)$ & 0.079 & $514(0.9)$ & $817(1.4)$ & 0.049 \\
\hline CKD (\%) & 14995 (1.9) & $532(0.9)$ & 0.089 & $801(1.4)$ & $497(0.8)$ & 0.050 \\
\hline ESRD (\%) & $5490(0.7)$ & $356(0.6)$ & 0.015 & $405(0.7)$ & $304(0.5)$ & 0.022 \\
\hline IHD (\%) & $36799(4.7)$ & $1572(2.6)$ & 0.114 & $2430(4.1)$ & $1518(2.6)$ & 0.086 \\
\hline Hypertension (\%) & $105284(13.4)$ & $4224(6.9)$ & 0.218 & $6359(10.9)$ & $4090(7.0)$ & 0.136 \\
\hline Statin use (\%) & $52698(6.7)$ & $1170(1.9)$ & 0.239 & $3149(5.4)$ & $1142(1.9)$ & 0.183 \\
\hline Mood and anxiety disorder (\%) & $270332(34.4)$ & $23440(38.1)$ & 0.076 & $22159(37.8)$ & $21594(36.9)$ & 0.020 \\
\hline Obesity (\%) & $19043(2.4)$ & 967 (1.6) & 0.061 & $990(1.7)$ & $950(1.6)$ & 0.005 \\
\hline Alcohol use disorder (\%) & $30368(3.9)$ & $10286(16.7)$ & 0.432 & $8943(15.3)$ & $8458(14.4)$ & 0.023 \\
\hline Injection drug use (\%) & $18789(2.4)$ & $11172(18.1)$ & 0.537 & $8780(15.0)$ & $8529(14.6)$ & 0.012 \\
\hline
\end{tabular}

${ }^{*}$ The propensity score (PS)-matched dataset was created by matching individuals with $\mathrm{HCV}$ infection with individuals without infection with a caliper of 0.1 at a 1:1 ratio without replacement. PS was estimated based on age at HCV diagnosis, duration of follow-up, sex, material/social deprivation quintiles, HBV/HIV infection, mood and anxiety disorders, obesity, alcohol use disorder and injection drug use.

tOther included white, Indigenous, black, Latin American, Pacific Islander, Central/West Asian, Filipino, Southeast Asian and other residents of British Columbia. CKD, chronic kidney disease; DQ, deprivation quintiles; ESRD, end-stage renal disease; HBV, hepatitis B virus; HCV, hepatitis C virus; HIV, human immunodeficiency virus; IHD, ischemic heart disease; PS, propensity scores; Q, quintile; SD, standard deviation; SMD, standardized mean difference.

1.30) ) and South Asians without HCV infection had 2.34 times higher hazard of diabetes (aHR $2.34(95 \%$ CI 1.98 to 2.77)). Other group with HCV infection had 2.27 times greater hazard of diabetes compared with the same group without infection (aHR 2.27 (95\% CI 2.14 to 2.41)). East Asians with HCV infection had 3.24 times greater hazard (aHR 3.24 (95\% CI 2.76 to 3.81$)$ ) and South Asians with HCV infection 


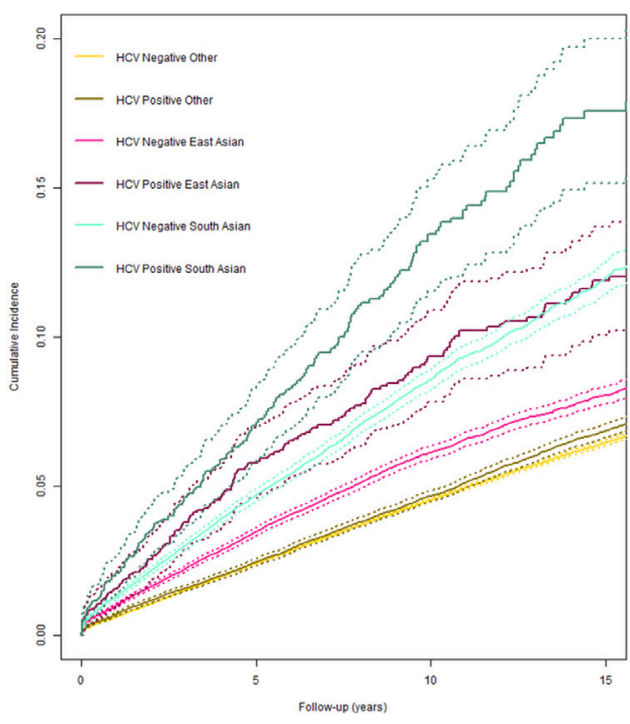

A

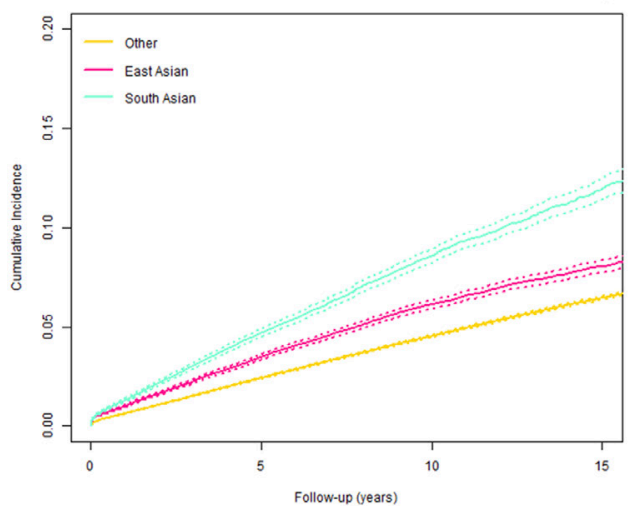

B

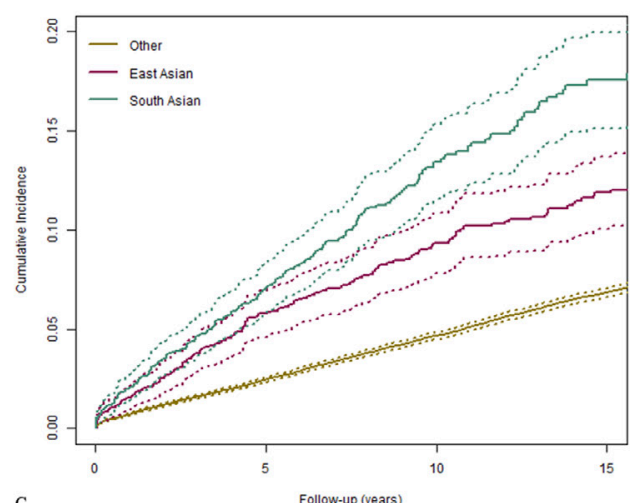

Figure 2 The 15-year cumulative incidence curves for diabetes by hepatitis $\mathrm{C}$ virus ( $\mathrm{HCV}$ ) infection status and ethnicity from the British Columbia Hepatitis Testers Cohort 1990-2015. (A) Cumulative incidence of diabetes in individuals with and without HCV infection by ethnicity, over 15 years of follow-up. Online supplemental table 3 presents overall incidence rates and 15-year cumulative incidences.

Solid lines: cumulative incidence of type 2 diabetes; dashed lines: $95 \%$ confidence intervals. (B) Cumulative incidence of diabetes in individuals without HCV infection by ethnicity, over 15 years of follow-up. (C) Cumulative incidence of diabetes in individuals with and without HCV infection by ethnicity, over 15 years of follow-up. Online supplemental table 3 presents overall incidence rates and 15-year cumulative incidences. Solid lines: cumulative incidence of type 2 diabetes; dashed lines: 95\% confidence intervals.
Table 2 Impact of HCV infection on diabetes risk between 1990-2015 in British Columbia Hepatitis Testers Cohort, using multivariable Fine-Gray subdistribution proportional hazards models

\begin{tabular}{|c|c|c|}
\hline Covariate & $\begin{array}{l}\text { aHR }(95 \% \mathrm{Cl}) \\
\text { PS-matched dataset }{ }^{*}\end{array}$ & $\begin{array}{l}\text { aHR }(95 \% \mathrm{CI}) \\
\text { PS-weighted dataset }+\end{array}$ \\
\hline HCV positive & 2.32 (2.20 to 2.45$)$ & 2.29 (2.17 to 2.42$)$ \\
\hline Male sex & $1.16(1.10$ to 1.23$)$ & 1.15 (1.09 to 1.21$)$ \\
\hline \multicolumn{3}{|c|}{ Age at HCV diagnosis (years) } \\
\hline$<25$ & 1 (ref) & 1 (ref) \\
\hline $25-34$ & 1.82 (1.51 to 2.19$)$ & 1.71 (1.42 to 2.05$)$ \\
\hline $35-44$ & 3.18 (2.67 to 3.79$)$ & 2.95 (2.48 to 3.51$)$ \\
\hline $45-54$ & 5.81 (4.88 to 6.92$)$ & 5.49 (4.62 to 6.52$)$ \\
\hline$\geq 55$ & 9.11 (7.62 to 10.89$)$ & 8.57 (7.19 to 10.22$)$ \\
\hline \multicolumn{3}{|l|}{ Ethnicity } \\
\hline Other & 1 (ref) & 1 (ref) \\
\hline East Asian & $1.26(1.12$ to 1.41$)$ & 1.30 (1.16 to 1.46$)$ \\
\hline South Asian & 2.46 (2.20 to 2.74$)$ & 2.48 (2.22 to 2.77$)$ \\
\hline \multicolumn{3}{|c|}{ Material deprivation quintiles } \\
\hline $\begin{array}{l}\text { Q1 (most } \\
\text { privileged) }\end{array}$ & 1 (ref) & 1 (ref) \\
\hline Q2 & 1.11 (1.01 to 1.23$)$ & 1.12 (1.02 to 1.24$)$ \\
\hline Q3 & 1.18 (1.08 to 1.30$)$ & 1.17 (1.07 to 1.28$)$ \\
\hline Q4 & 1.14 (1.04 to 1.25$)$ & $1.13(1.04$ to 1.24$)$ \\
\hline $\begin{array}{l}\text { Q5 (most } \\
\text { deprived) }\end{array}$ & 1.18 (1.08 to 1.29$)$ & 1.17 (1.07 to 1.27$)$ \\
\hline \multicolumn{3}{|c|}{ Social deprivation quintiles } \\
\hline $\begin{array}{l}\text { Q1 (most } \\
\text { privileged) }\end{array}$ & 1 (ref) & 1 (ref) \\
\hline Q2 & 1.07 (0.97 to 1.18$)$ & 1.01 (0.92 to 1.12$)$ \\
\hline Q3 & 0.99 (0.90 to 1.09$)$ & 0.96 (0.87 to 1.05$)$ \\
\hline Q4 & $1.01(0.92$ to 1.11$)$ & 0.97 (0.88 to 1.06$)$ \\
\hline $\begin{array}{l}\text { Q5 (most } \\
\text { deprived) }\end{array}$ & 0.95 (0.87 to 1.04$)$ & $0.92(0.84$ to 1.00$)$ \\
\hline Obesity & 2.42 (2.11 to 2.77$)$ & 2.49 (2.17 to 2.86$)$ \\
\hline HBV positive & $1.15(0.93$ to 1.41$)$ & 1.14 (0.93 to 1.40$)$ \\
\hline HIV positive & 1.50 (1.09 to 1.89$)$ & 0.99 (0.81 to 1.19$)$ \\
\hline $\begin{array}{l}\text { Mood and } \\
\text { anxiety disorder }\end{array}$ & 1.15 (1.09 to 1.22$)$ & 1.18 (1.11 to 1.25$)$ \\
\hline $\begin{array}{l}\text { Alcohol use } \\
\text { disorder }\end{array}$ & $1.23(1.14$ to 1.33$)$ & 1.11 (1.03 to 1.20$)$ \\
\hline $\begin{array}{l}\text { Injection drug } \\
\text { use }\end{array}$ & $1.38(1.27$ to 1.50$)$ & 1.05 (0.97 to 1.14$)$ \\
\hline
\end{tabular}

${ }^{*}$ The propensity score (PS)-matched dataset was created by matching individuals with $\mathrm{HCV}$ infection with individuals without infection with a caliper of 0.1 at a $1: 1$ ratio without replacement. PS was estimated based on age at HCV diagnosis, duration of follow-up, sex, material/ social deprivation quintiles, HBV/HIV infection, mood and anxiety disorders, obesity, alcohol use disorder and injection drug use. †The PS-weighted dataset used inverse probability weights (IPW) estimating the average treatment effect on the treated (ATT). PS were estimated based on age at HCV diagnosis, duration of follow-up, sex, material/social deprivation quintiles, HBV/HIV infection, mood and anxiety disorders, obesity, alcohol use disorder and injection drug use.

aHR, adjusted hazard ratios; $\mathrm{Cl}$, confidence interval; HBV, hepatitis $\mathrm{B}$ virus; $\mathrm{HCV}$, hepatitis $\mathrm{C}$ virus; HIV, human immunodeficiency virus; $P S$, propensity scores; $\mathrm{Q}$, quintile. 
Table 3 Impact of HCV infection and ethnicity on diabetes risk between 1990-2015 in British Columbia Hepatitis Testers Cohort, using multivariable Fine-Gray subdistribution proportional hazards models*

\begin{tabular}{lll}
\hline Covariate & $\begin{array}{l}\text { aHR (95\% CI), } \\
\text { PS-matched } \\
\text { dataset }\end{array}$ & $\begin{array}{l}\text { aHR (95\% CI), } \\
\text { PS-weighted } \\
\text { dataset }\end{array}$ \\
\hline $\begin{array}{l}\text { HCV-negative } \\
\text { Other }\end{array}$ & 1 (ref) & 1 (ref) \\
$\begin{array}{l}\text { HCV-negative } \\
\text { East Asian }\end{array}$ & $1.10(0.93$ to 1.30$)$ & $1.21(1.02$ to 1.42$)$ \\
$\begin{array}{l}\text { HCV-negative } \\
\text { South Asian }\end{array}$ & $2.34(1.98$ to 2.77$)$ & $2.42(2.05$ to 2.87$)$ \\
$\begin{array}{l}\text { HCV-positive } \\
\text { Other }\end{array}$ & $2.27(2.14$ to 2.41$)$ & $3.18(2.70$ to 3.73$)$ \\
$\begin{array}{l}\text { HCV-positive } \\
\text { East Asian }\end{array}$ & $3.24(2.76$ to 3.81$)$ & $2.27(2.14$ to 2.40$)$ \\
$\begin{array}{l}\text { HCV-positive } \\
\text { South Asian }\end{array}$ & $5.76(4.98$ to 6.67$)$ & $5.71(4.93$ to 6.60$)$ \\
\hline
\end{tabular}

*Multivariable models were adjusted with sex, age at HCV diagnosis, material and social deprivation quintiles, HBV/HIV infection, obesity, mood and anxiety disorders, alcohol use disorder and injection drug use.

aHR, adjusted hazard ratios; $\mathrm{Cl}$, confidence interval; $\mathrm{HCV}$, hepatitis $\mathrm{C}$ virus; PS, propensity scores.

had 5.76 times greater hazard (aHR 5.76 (95\% CI 4.98 to 6.67$)$ ) compared with 'Other without HCV infection' group. IPW ATT weighted analysis showed similar aHR (table 3). Online supplemental figure 1 illustrates the impact of HCV infection and ethnicity on diabetes risk, adjusting for covariates.

In further analysis, the subdistributional hazards were calculated with Fine-Gray models in the matched dataset stratified by ethnicity (online supplemental table 4). Although the $95 \%$ CIs overlap between South Asian people and Others, aHRs associated with diabetes were greater for individuals with HCV infection in East Asian and South Asian people, compared with Others: among East Asians, people with HCV had 3.07 times higher hazards (95\% CI 2.43 to 3.88); among South Asians, people with HCV had 2.62 times higher hazards (95\% CI 2.10 to 3.26), and all other people with HCV had 2.28 times higher hazards (95\% CI 2.15 to 2.42 ) of diabetes compared with those without infection. Lastly, when we estimated PS in each subgroup separately and matched on PS within each subgroup as a further sensitivity analysis, similar aHRs were observed (online supplemental table 5).

\section{DISCUSSION}

\section{Summary of the study findings}

In this large, population-based longitudinal cohort of 847021 individuals in British Columbia, we found a higher incidence rate of type 2 diabetes in individuals with HCV infection compared with those without (5.85 vs 5.40 per 1000 PYFU, respectively; p value $<0.001)$.
The highest diabetes incidence rate was in South Asian people with HCV infection, with 14.7 cases of incident diabetes per 1000 PYFU (95\% CI 12.87 to 16.78). Furthermore, the incidence rates of diabetes were higher in both people with and without HCV infection among East Asian and South Asian people, compared with the overall population. The findings from both PS matched and weighted analyses showed that individuals with $\mathrm{HCV}$ infection were more than twice as likely to develop type 2 diabetes compared with those without infection. The incidence rate of diabetes in non-Asian $\mathrm{BC}$ residents without $\mathrm{HCV}$ infection was 5.02/1000 PYFU (95\% CI 4.96 to 5.08) compared with 5.56/1000 PYFU (95\% CI 5.39 to 5.74) in those with infection. It is important to note that these incidence rates are unadjusted. By matching individuals with $\mathrm{HCV}$ infection to those without infection based on PS to create balance in the baseline characteristics, and by adjusting for confounders such as sex, age and other comorbidities, we assessed the effect of HCV infection on incidence of diabetes while minimizing bias. Furthermore, when looking at the combined effect of HCV infection and ethnicity, we observed an increased risk of diabetes associated with HCV infection across all ethnicities. South Asian people had the greatest diabetes risk compared with Others. Of note, East Asian people without HCV infection had a similar diabetes risk as Others without infection; however, with HCV infection, this risk was much higher compared with Others with HCV infection, reinforcing the potential of effect modification in East Asian people. The stratified analysis in each ethnic group showed that HCV infection may have a greater impact on diabetes risk in Asian population compared with Others. Based on current evidence, it is unclear why chronic HCV infection may have a greater impact on diabetes risk in East Asians. However, it is known that Asian population has a higher risk of developing non-alcoholic fatty liver disease (NAFLD) with lower weight and BMI compared with other ethnic groups, which in turn can also increase the risk of developing metabolic diseases. ${ }^{41-43}$ It is suggested that differential distribution of visceral adipose tissue, high cholesterol diet and genetic background may be associated with the development of NAFLD in Asian people. ${ }^{41}$ Perhaps chronic liver diseases such as NAFLD or hepatitis C infection have a greater impact on developing diabetes in Asian population due to genetic or biological differences in gastrointestinal disorders. More research is needed to understand the ethnic differences in the relationship between HCV infection and diabetes.

\section{Comparison with existing literature}

Overall, the findings from this study support the mounting evidence in the literature that showed an association between HCV infection and metabolic diseases. ${ }^{4-7}$ In a cohort study based in Taiwan, Lin et a $\tilde{l}^{\tilde{l}}$ found that 
individuals with HCV infection had over $60 \%$ higher hazard of developing diabetes compared with those without infection (aHR 1.63 (95\% CI 1.31 to 2.02)). Our analysis indicated an even higher hazard, as individuals with HCV infection in the BC-HTC experienced more than 2.32 times higher hazard for diabetes than those without infection. Furthermore, this analysis showed an increased risk of diabetes in Asian population. In East Asian people, HCV infection had the greatest relative impact on incident diabetes compared with other groups (aHR 3.07 (95\% CI 2.43 to 3.88)). On the other hand, South Asian people had the greatest risk of diabetes with and without HCV infection compared with other groups. Previous studies based in the USA have shown the presence of ethnic disparities in diabetes ${ }^{44-46}$; however, there is limited evidence on the impact of HCV infection on diabetes in South and East Asian population. Asians have a high prevalence of cardiometabolic diseases and South Asians have a particularly high risk of diabetes. ${ }^{18} 194748$ Burden of HCV is very high in some Asian countries such as Pakistan, India and China. ${ }^{49} \mathrm{HCV}$ infection may further increase the risk of diabetes in populations with higher burden of diabetes if HCV is not treated early in the course of infection. Our findings suggest that existing disparities in diabetes burden could be further exacerbated by HCV. However, curative HCV treatment could reduce HCV indented disparities in diabetes burden.

\section{Strengths and limitations}

This study has several strengths. First, to our knowledge, this is one of the first studies that used large-scale linked administrative data to illustrate the characteristics of people who developed diabetes following a positive HCV diagnosis. The large sample size and sufficient follow-up time in the BC-HTC allowed us to estimate the effect of $\mathrm{HCV}$ infection on incident diabetes at a population level. Second, as the BC-HTC is a longitudinal cohort data, ${ }^{26}$ it was possible to establish the temporality in the association between HCV infection and type 2 diabetes. Even though this is an observational study, analyses using PS allowed for a less biased assessment of the impact of HCV infection on incident diabetes by balancing the baseline characteristics between individuals living with and without HCV infection. ${ }^{34}$ Moreover, the robustness of our findings is supported by the consistent results from the PS-matched dataset and the overall weighted dataset. In addition, studies assessing the impact of HCV infection on diabetes across different ethnic groups are scarce. In this analysis, we were able to identify South and East Asian people in the study cohort with high specificity. In an internal validation study, Nam Pechan had high sensitivity $(91.2 \%)$ and specificity $(95.9 \%)$ for identifying South Asians, and Onomap identified East Asians with high sensitivity $(99.5 \%)$ but lower sensitivity (66.7\%). Although there may still be some misclassification of South and East Asians in the 'Other' group, this would have biased the estimates toward the null. By analyzing data from the ethnically diverse population of $\mathrm{BC}$, we were able to examine and compare the impact of $\mathrm{HCV}$ infection on diabetes in East and South Asian people compared with Others.

Finally, as the BC-HTC is linked with various administrative data, we have accounted for several important confounders as well as the competing risk of mortality to estimate a more accurate measure of association between HCV and diabetes. The BC-HTC is a comprehensive population-based cohort representative of the BC population, ${ }^{26}$ which improves the generalizability of our results.

This study also has several limitations and the findings should be interpreted with caution. As the BC-HTC is based on linked health administrative data, study variables were assessed from administrative information. Diabetes and obesity are particularly challenging to identify from these types of data as many cases, such as prediabetes, may not be formally diagnosed and may lead to some misclassification. However, this misclassification is likely to be non-differential between individuals with or without HCV infection and the bias would be toward the null. There remains some unmeasured confounding, ${ }^{50}$ such as individuals' education level, smoking history, BMI, diet and lifestyle factors, and serum levels of lipids. For instance, it has been suggested previously that whether or not an association is found between HCV infection and diabetes is influenced by the inclusion of indicators such as bilirubin, lipid and albumin serum levels which demonstrate liver and kidney functions, information that is not available in this analysis. ${ }^{51}$ To mitigate the residual confounding, we adopted a double-robust approach after matching based on PS, by adjusting for covariates again in the Fine-Gray subdistribution proportional hazards models. ${ }^{38}$

\section{CONCLUSION}

Individuals who are affected by diabetes and HCV infection concurrently are at an increased risk of other morbidities, including the progression of liver-related and non-liver-related diseases, and mortality. ${ }^{52}$ Our analysis showed that HCV infection increases the risk of diabetes in the overall population and has a greater relative impact on diabetes in East Asian people compared with other ethnicities. Moreover, South Asian population experienced the greatest risk of diabetes even without $\mathrm{HCV}$ infection, and the risk increased further with infection. Several studies have shown that successful HCV treatment among HCV-positive individuals is, in turn, associated with decreased incidence of diabetes. ${ }^{53-56}$ These findings indicate that early treatment of HCV infection may reduce disparities in diabetes incidence to some extent. Based on the increased diabetes risk associated with chronic HCV infection among East Asian people and the relative high risk of diabetes in South Asian people, it is essential to scale up the care and screening programs for not only chronic HCV infection but also diabetes and other metabolic diseases. The results of this study further 
highlight the need for early diagnosis of HCV infection, linkage to care and continued care and screening for HCV-related chronic diseases.

\section{Author affiliations}

${ }^{1}$ School of Population and Public Health, The University of British Columbia, Vancouver, British Columbia, Canada

${ }^{2}$ Clinical Prevention Services, British Columbia Centre for Disease Control, Vancouver, British Columbia, Canada

${ }^{3}$ Centre for Health Evaluation and Outcome Sciences, St Paul's Hospital, Vancouver, British Columbia, Canada

${ }^{4}$ School of Public Health and Health Systems, University of Waterloo, Waterloo, Ontario, Canada

${ }^{5}$ Department of Pathology and Laboratory Medicine, The University of British Columbia, Vancouver, British Columbia, Canada

${ }^{6}$ Faculty of Health Sciences, Simon Fraser University, Burnaby, British Columbia, Canada

Twitter Dahn Jeong @Dahn_Jeong, Mohammad Ehsanul Karim @ehsan7x, Prince Asumadu Adu @theprinceadu, Sofia Bartlett @SofiaRB_88,Emilia Clementi @emilia_clementi, Hasina Samji @HasinanisaH and Naveed Zafar Janjua @ naveedjanjua

Acknowledgements We thank the British Columbia Centre for Disease Control, Providence Health Services Authority, British Columbia Ministry of Health, British Columbia Cancer Agency and their respective program staff involved in data access, procurement and data management for their assistance.

Contributors NZJ, MK, SW, AY, and MA participated in the data acquisition. DJ and NZJ conceived the analysis and designed the study. DJ performed analyses, wrote the first draft of the paper and incorporated revisions by NZJ and MEK. All authors contributed to data interpretation and manuscript revisions.

Funding This work was supported by the $\mathrm{BC}$ Centre for Disease Control and the Canadian Institutes of Health Research (CIHR) (Grant \# NHC-348216, PJT-156066, and PHE-337680).

Disclaimer All inferences, opinions, and conclusions drawn in this analysis are those of the authors and do not necessarily reflect the opinions or policies of the British Columbia Ministry of Health and the Data Steward(s).

Competing interests DJ is supported by the CIHR Frederick Banting and Charles Best Doctoral Award and the Canadian Network on Hepatitis C PhD fellowship. MEK is supported by the Michael Smith Foundation for Health Research Scholar award and holds research grants from the Natural Sciences and Engineering Research Council of Canada and BC SUPPORT Unit. Over the past 3 years, MEK has received consulting fees from Biogen (unrelated to this project). MK has received grant/ research support from Roche, Merck, Siemens, Boehringer Ingelheim and Hologic. SW, JW, ZAB, MB, PAA, SB, MP, EC, AY, MA, HS, HAVG, YA and NZJ have no conflicts of interest to declare.

\section{Patient consent for publication Not required.}

Ethics approval Data linkages to create the BC-HTC were enabled under the auspices of the BCCDC's public health mandate and were reviewed and approved by the University of British Columbia Behavioural Research Ethics Board (No: H14-01649).

Provenance and peer review Not commissioned; externally peer reviewed.

Data availability statement Data are available on reasonable request. Data are available from the $\mathrm{BC}$ Centre for Disease Control Institutional Data Access for researchers who meet the criteria for access to confidential data. Requests for the data may be sent to Dr Naveed Janjua (naveed.janjua@bccdc.ca).

Supplemental material This content has been supplied by the author(s). It has not been vetted by BMJ Publishing Group Limited (BMJ) and may not have been peer-reviewed. Any opinions or recommendations discussed are solely those of the author(s) and are not endorsed by BMJ. BMJ disclaims all liability and responsibility arising from any reliance placed on the content. Where the content includes any translated material, BMJ does not warrant the accuracy and reliability of the translations (including but not limited to local regulations, clinical guidelines, terminology, drug names and drug dosages), and is not responsible for any error and/or omissions arising from translation and adaptation or otherwise.

Open access This is an open access article distributed in accordance with the Creative Commons Attribution Non Commercial (CC BY-NC 4.0) license, which permits others to distribute, remix, adapt, build upon this work non-commercially, and license their derivative works on different terms, provided the original work is properly cited, appropriate credit is given, any changes made indicated, and the use is non-commercial. See: http://creativecommons.org/licenses/by-nc/4.0/.

ORCID iDs

Dahn Jeong http://orcid.org/0000-0003-1782-5669

Héctor Alexander Velásquez García http://orcid.org/0000-0002-0764-4664

\section{REFERENCES}

1 Fabrizi F, Messa P. The epidemiology of HCV infection in patients with advanced CKD/ESRD: a global perspective. Semin Dial 2019;32:93-8.

2 Cacoub P, Comarmond C, Domont F, et al. Extrahepatic manifestations of chronic hepatitis $\mathrm{C}$ virus infection. Ther Adv Infect Dis 2016;3:3-14.

3 Morgan RL, Baack B, Smith BD, et al. Eradication of hepatitis C virus infection and the development of hepatocellular carcinoma: a metaanalysis of observational studies. Ann Intern Med 2013;158:329-37.

4 White DL, Ratziu V, El-Serag HB. Hepatitis C infection and risk of diabetes: a systematic review and meta-analysis. $J$ Hepatol 2008;49:831-44.

5 Lin Y-J, Shaw T-WG, Yang H-I, et al. Chronic hepatitis C virus infection and the risk for diabetes: a community-based prospective study. Liver Int 2017;37:179-86.

6 Gastaldi G, Goossens N, Clément S, et al. Current level of evidence on causal association between hepatitis $C$ virus and type 2 diabetes: a review. J Adv Res 2017:8:149-59.

7 Younossi ZM, Stepanova M, Nader F, et al. Associations of chronic hepatitis $C$ with metabolic and cardiac outcomes. Aliment Pharmacol Ther 2013;37:647-52.

8 Mehta SH, Brancati FL, Sulkowski MS, et al. Prevalence of type 2 diabetes mellitus among persons with hepatitis $C$ virus infection in the United States. Ann Intern Med 2000;133:592-9.

9 Stepanova M, Lam B, Younossi Y, et al. Association of hepatitis C with insulin resistance and type 2 diabetes in US general population: the impact of the epidemic of obesity. J Viral Hepat 2012;19:341-5.

10 Ruhl CE, Menke A, Cowie CC, et al. Relationship of hepatitis C virus infection with diabetes in the U.S. population. Hepatology 2014;60:1139-49.

11 Banerjee S, Saito K, Ait-Goughoulte M, et al. Hepatitis C virus core protein upregulates serine phosphorylation of insulin receptor substrate- 1 and impairs the downstream Akt/protein kinase B signaling pathway for insulin resistance. J Virol 2008;82:2606-12.

12 Loria P, Lonardo A, Anania F. Liver and diabetes. A vicious circle. Hepatol Res 2013;43:51-64.

13 Emmanuel B, Shardell MD, Tracy L, et al. Racial disparity in all-cause mortality among hepatitis $C$ virus-infected individuals in a general US population, NHANES III. J Viral Hepat 2017;24:380-8.

14 Thuluvath PJ, John PR. Association between hepatitis $C$, diabetes mellitus, and race. A case-control study. Am J Gastroenterol 2003:98:438-41.

15 Mukhtar NA, Ayala C, Maher JJ, et al. Assessment of factors associated with pre-diabetes in HCV infection including direct and dynamic measurements of insulin action. J Viral Hepat 2012;19:480-7.

16 Wong RJ, Ahmed A. Obesity and non-alcoholic fatty liver disease: disparate associations among Asian populations. World J Hepatol 2014;6:263-73.

17 Ferdinand KC, Nasser SA. Racial/Ethnic disparities in prevalence and care of patients with type 2 diabetes mellitus. Curr Med Res Opin 2015;31:913-23

18 Memon MS, Arain ZI, Naz F, et al. Prevalence of type 2 diabetes mellitus in hepatitis $C$ virus infected population: a Southeast Asian study. J Diabetes Res 2013;2013:1-7.

19 Rees SD, Hydrie MZI, O'Hare JP, et al. Effects of 16 genetic variants on fasting glucose and type 2 diabetes in South Asians: ADCY5 and Glis3 variants may predispose to type 2 diabetes. PLoS One 2011;6:e24710.

20 Census profile, 2016 census. Ottawa, 2017. Available: http://www12 statcan.gc.ca/census-recensement/2016/dp-pd/prof/details/page. $\mathrm{cfm}$ ? Lang $=E \& G e 01=P O P C \& C o d e 1=0620 \& G e 02=P R \& C o d e 2=47 \&$ Data $=$ Count\&SearchText=Oxbow\&SearchType=Begins\&SearchPR= $01 \& B 1=A l l \&$ TABID $=1$

21 Al Kanaani Z, Mahmud S, Kouyoumjian SP, et al. The epidemiology of hepatitis $C$ virus in Pakistan: systematic review and metaanalyses. $R$ Soc Open Sci 2018;5:180257.

22 Janjua NZ, Yu A, Kuo M, et al. Twin epidemics of new and prevalent hepatitis $\mathrm{C}$ infections in Canada: bc hepatitis testers cohort. BMC Infect Dis 2016;16:334. 
23 Diabetes Canada Clinical Practice Guidelines Expert Committee, Houlden RL. Introduction. Can J Diabetes 2018;42 Suppl 1:S1-5.

24 Health fact sheets: diabetes, 2017. Ottawa, on, 2018. Available: https://www150.statcan.gc.ca/n1/pub/82-625-x/2018001/article/ 54982-eng.htm [Accessed 18 Nov 2019].

25 Dyal HK, Aguilar M, Bartos G, et al. Diabetes mellitus increases risk of hepatocellular carcinoma in chronic hepatitis $C$ virus patients: a systematic review. Dig Dis Sci 2016;61:636-45.

26 Janjua NZ, Kuo M, Chong M, et al. Assessing hepatitis C burden and treatment effectiveness through the British Columbia hepatitis testers cohort (BC-HTC): design and characteristics of linked and unlinked participants. PLoS One 2016;11:e0150176.

27 Chen G, Khan N, Walker R, et al. Validating ICD coding algorithms for diabetes mellitus from administrative data. Diabetes Res Clin Pract 2010;89:189-95.

28 Ryan R, Vernon S, Lawrence G, et al. Use of name recognition software, census data and multiple imputation to predict missing data on ethnicity: application to cancer registry records. BMC Med Inform Decis Mak 2012;12:3.

29 Lakha F, Gorman DR, Mateos P. Name analysis to classify populations by ethnicity in public health: validation of Onomap in Scotland. Public Health 2011;125:688-96.

30 BIESP. Index of Material and Social Deprivation Compiled by the Bureau d'information et d'études En Santé Des Populations (BIESP) 2011. Available: https://www.inspq.qc.ca/en/expertise/informationmanagement-and-analysis/deprivation-index [Accessed $18 \mathrm{Nov}$ 2019].

31 Zhang Z, Kim HJ, Lonjon G, et al. Balance diagnostics after propensity score matching. Ann Trans/ Med 2019;7:16.

32 Stuart EA. Matching methods for causal inference: a review and a look forward. Stat Sci 2010;25:1-21.

33 Austin PC. A tutorial and case study in propensity score analysis: an application to estimating the effect of in-hospital smoking cessation counseling on mortality. Multivariate Behav Res 2011;46:119-51.

34 Austin PC. The use of propensity score methods with survival or time-to-event outcomes: reporting measures of effect similar to those used in randomized experiments. Stat Med 2014;33:1242-58.

35 Austin PC. Optimal caliper widths for propensity-score matching when estimating differences in means and differences in proportions in observational studies. Pharm Stat 2011;10:150-61.

36 Desai RJ, Franklin JM. Alternative approaches for confounding adjustment in observational studies using weighting based on the propensity score: a primer for practitioners. BMJ 2019;367:I5657-10.

37 Fine JP, Gray RJ. A proportional hazards model for the Subdistribution of a competing risk. J Am Stat Assoc 1999;94:496-509.

38 Nguyen T-L, Collins GS, Spence J, et al. Comparison of the ability of double-robust estimators to correct bias in propensity score matching analysis. A Monte Carlo simulation study. Pharmacoepidemiol Drug Saf 2017;26:1513-9.

39 SAS Institute Inc. SAS Institute Inc, 2017.
40 R Core Team. R: a language and environment for statistical computing, 2019. Available: https://www.r-project.org

41 Liu C-J. Prevalence and risk factors for non-alcoholic fatty liver disease in Asian people who are not obese. J Gastroenterol Hepatol 2012;27:1555-60.

42 Fan J-G, Kim S-U, Wong VW-S. New trends on obesity and NAFLD in Asia. J Hepatol 2017;67:862-73.

43 Golabi P, Paik J, Hwang JP, et al. Prevalence and outcomes of nonalcoholic fatty liver disease (NAFLD) among Asian American adults in the United States. Liver Int 2019;39:748-57.

44 Huang ZJ, Zheng C. Type 2 diabetes among 6 Asian ethnic groups in California: the nexus of ethnicity, gender, and generational status. $J$ Health Care Poor Underserved 2015;26:16-35.

45 Banks DE, Bogler Y, Bhuket T, et al. Significant disparities in risks of diabetes mellitus and metabolic syndrome among chronic hepatitis C virus patients in the U.S. Diabetes Metab Syndr 2017;11:S153-8.

46 Lim E, Gandhi K, Davis J, et al. Prevalence of chronic conditions and Multimorbidities in a geographically defined geriatric population with diverse races and ethnicities. J Aging Health 2018;30:421-44.

47 Geldsetzer P, Manne-Goehler J, Theilmann M, et al. Diabetes and hypertension in India: a nationally representative study of 1.3 million adults. JAMA Intern Med 2018;178:363.

48 Banerjee AT, Shah BR. Differences in prevalence of diabetes among immigrants to Canada from South Asian countries. Diabet Med 2018;35:937-43.

49 Polaris Observatory HCV Collaborators. Global prevalence and genotype distribution of hepatitis $C$ virus infection in 2015: a modelling study. Lancet Gastroenterol Hepatol 2017;2:161-76.

50 Barrowman MA, Peek N, Lambie M, et al. How unmeasured confounding in a competing risks setting can affect treatment effect estimates in observational studies. BMC Med Res Methodol 2019;19:166.

51 Zhao P, Wei Z, Liu W. Is there a straightforward relationship between hepatitis $\mathrm{C}$ virus infection and diabetes? Hepatology 2015;61:1097-8.

52 Younossi Z, Park H, Henry L, et al. Extrahepatic Manifestations of Hepatitis C: A Meta-analysis of Prevalence, Quality of Life, and Economic Burden. Gastroenterology 2016;150:1599-608.

53 Hum J, Jou JH. The link between hepatitis $\mathrm{C}$ virus and diabetes mellitus: improvement in insulin resistance after eradication of hepatitis C virus. Clin Liver Dis 2018;11:73-6.

$54 \mathrm{Li} \mathrm{J}$, Zhang T, Gordon SC, et al. Impact of sustained virologic response on risk of type 2 diabetes among hepatitis $C$ patients in the United States. J Viral Hepat 2018;25:952-8.

55 Gastaldi G, Gomes D, Schneiter P, et al. Treatment with direct-acting antivirals improves peripheral insulin sensitivity in non-diabetic, lean chronic hepatitis C patients. PLoS One 2019;14:1-17.

56 Rossi C, Jeong D, Wong S, et al. Sustained virological response from interferon-based hepatitis $C$ regimens is associated with reduced risk of extrahepatic manifestations. J Hepatol 2019;71:1116-25. 